\title{
Stable isotopes of Hawaiian spiders reflect substrate properties along a chronosequence
}

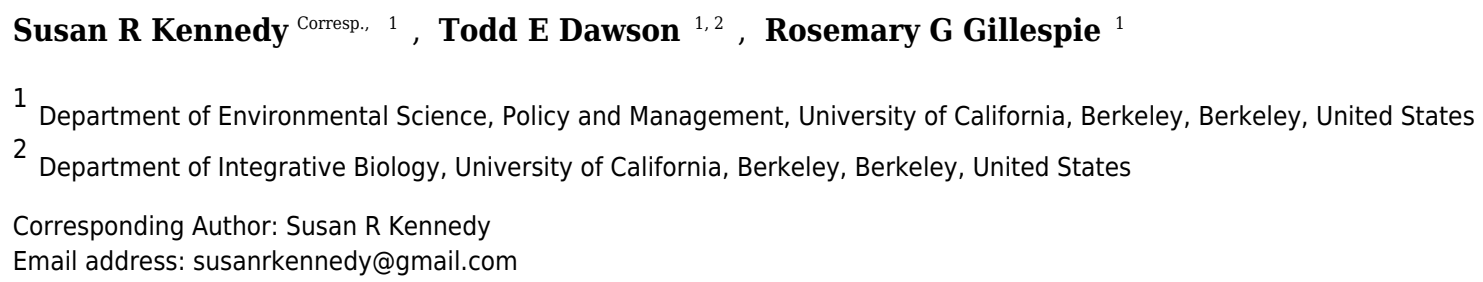

The Hawaiian Islands offer a unique opportunity to test how changes in the properties of an isolated ecosystem are propagated through the organisms that occur within that ecosystem. The age-structured arrangement of volcanic-derived substrates follows a regular progression over space and, by inference, time. We test how well documented successional changes in soil chemistry and associated vegetation are reflected in organisms at higher trophic levels - specifically, predatory arthropods (spiders) - across a range of functional groups. We focus on three separate spider lineages: one that builds capture webs, one that hunts actively, and one that specializes on eating other spiders. We analyze spiders from three sites across the Hawaiian chronosequence with substrate ages ranging from 200 to 20,000 years. To measure the extent to which chemical signatures of terrestrial substrates are propagated through higher trophic levels, we use standard stable isotope analyses of nitrogen and carbon, with plant leaves included as a baseline. The target taxa show the expected shift in isotope ratios of $\delta^{15} \mathrm{~N}$ with trophic level, from plants to cursorial spiders to web-builders to spider eaters. Remarkably, organisms at all trophic levels also precisely reflect the successional changes in the soil stoichiometry of the island chronosequence, demonstrating how the biogeochemistry of the entire food web is determined by ecosystem succession of the substrates on which the organisms have evolved. 


\section{Title}

2 Stable isotopes of Hawaiian spiders reflect substrate properties along a chronosequence

3

\section{Authors}

5 Susan R. Kennedy ${ }^{1}$, Todd E. Dawson ${ }^{1,2}$, Rosemary G. Gillespie ${ }^{1}$

6

7 1: Department of Environmental Science, Policy, \& Management,

8 University of California, Berkeley,

9 Berkeley,

10 United States

11

12 2: Department of Integrative Biology,

13 University of California, Berkeley,

14 Berkeley,

15 United States

16

17

18

19

20 Corresponding Author: Susan Kennedy (Orcid ID: 0000-0002-1616-3985)

21 susanrkennedy@gmail.com 


\section{Abstract}

23 The Hawaiian Islands offer a unique opportunity to test how changes in the properties of an

24 isolated ecosystem are propagated through the organisms that occur within that ecosystem.

25 The age-structured arrangement of volcanic-derived substrates follows a regular progression

26 over space and, by inference, time. We test how well documented successional changes in soil

27 chemistry and associated vegetation are reflected in organisms at higher trophic levels specifically, predatory arthropods (spiders) - across a range of functional groups. We focus on three separate spider lineages: one that builds capture webs, one that hunts actively, and one that specializes on eating other spiders. We analyze spiders from three sites across the Hawaiian chronosequence with substrate ages ranging from 200 to 20,000 years. To measure the extent to which chemical signatures of terrestrial substrates are propagated through higher trophic levels, we use standard stable isotope analyses of nitrogen and carbon, with plant leaves included as a baseline. The target taxa show the expected shift in isotope ratios of $\delta^{15} \mathrm{~N}$ with trophic level, from plants to cursorial spiders to web-builders to spider eaters. Remarkably, organisms at all trophic levels also precisely reflect the successional changes in the soil

37 stoichiometry of the island chronosequence, demonstrating how the biogeochemistry of the

38 entire food web is determined by ecosystem succession of the substrates on which the 39 organisms have evolved.

\section{Introduction}

41 Evolutionary processes are determined in large part by the ecosystems within which they take 42 place. While connecting the processes of evolutionary biology and ecology remains a critical 43 frontier in biological sciences (Matthews et al. 2011), there are few studies that demonstrate 
44 how mechanisms driving processes of evolutionary biology and ecosystem science are linked.

45 The current study seeks to understand how organismal diversity may reflect successional shifts

46 in soil chemistry by testing the extent to which organisms at different trophic levels reflect the

47 properties of the substrates on which they occur.

48

49 The Hawaiian Archipelago presents a highly suitable system for studying the link between

50 evolutionary processes and ecosystem properties. The current high islands of Hawaii are

51 arranged sequentially from oldest to youngest, with Kauai, at 5.1 million years, in the far

52 northwest, and Hawai'i Island, at <1 million years, in the southeast (Carson and Clague 1995).

53 This sequential order is a consequence of the archipelago being located on a volcanic hot spot,

54 where magma upwelling from the earth's mantle has formed into large shield volcanoes. At the

55 same time, the tectonic plate on which the islands are situated is moving toward the northwest

56 such that each newly emerging island has appeared to the southeast of its next-oldest neighbor.

57 The resultant, nearly-linear age gradient makes Hawaii an ideal chronosequence: a temporally

58 varied system in which the ecosystems of the younger sites are currently developing in a

59 manner assumed to reflect the developmental history of the older sites (Walker et al. 2010).

60 Given fairly precise information on the age of formation and subsequent history across a

61 chronosequence, these systems can provide unprecedented insights into ecosystem

62 development. Thus, chronosequences have added significantly to our understanding of how

63 nutrients change over time (Vitousek 2004) and the impact of changes in soil nutrient availability

64 on plants (Wardle et al. 2008), decomposers (Williamson et al. 2005, Doblas-Miranda et al.

65 2008), above-ground and below-ground ecosystem processes (Wardle et al. 2004), and entire

66 arthropod communities (Gruner 2007).

67

68 Hawaii has served as a chronosequence for detailed studies on the ways in which ecosystem

69 properties and functions change over extended time (Vitousek 2004). Nutrient flow and its 
70 impacts on primary producers (trees) have been well characterized in this system. Studies have

71 examined the evolution of soils on substrates of different surficial age (300 y -4.1 Mya),

72 controlled for elevation, climate, land use history, and canopy vegetation (Metrosideros

73 polymorpha), with all minerals derived from volcanic ash. An important finding of this work was

74 that soil nitrogen, foliar nutrient availability and productivity start off very low, increase rapidly

75 with substrate age, peak on substrates of intermediate age (ca. 20,000 y) on the youngest

76 island, and then decline rapidly on older islands before all but disappearing on the oldest

77 (Vitousek et al. 1989, 1995, 1997). A more recent study found that tree height and canopy

78 nitrogen also peak on intermediate-aged $(20,000 \mathrm{y})$ substrates on the youngest island (Vitousek

79 et al. 2009). Nitrogen isotopes follow a similar pattern, with foliar $\delta^{15} \mathrm{~N}$ very low at the youngest

80 sites, increasing with substrate age, and highest at a 67,000 y site (Vitousek et al. 1989).

81

82 Geologic history and nutrient flow evidently have important effects on the lowest trophic level -

83 plants - but little is known about how these effects might be propagated through higher trophic

84 levels, i.e. higher-level consumers. At the same time, work on the effects of substrate age on

85 above-ground systems, including whole communities, has shown that community traits such as

86 population species diversity (Gillespie and Baldwin 2010, Lim and Marshall 2017), genetic

87 structure (Roderick et al. 2012), and network modularity (Rominger et al. 2016) change in a

88 predictable manner across the Hawaiian chronosequence. However, although these

89 community-level studies have markedly enhanced our understanding of the changes in

90 community ecology over time, there has as yet been no attempt to link chemical changes during

91 the evolution and development of soils (and associated ecosystem properties) with the

92 abundance, diversity, and evolutionary histories of above-ground organisms. The current study

93 begins to address this question by testing the effects of substrate age on the biochemistry -

94 isotopic signatures - of secondary consumers (predators) across a Hawaiian chronosequence. 
96 The application of stable isotope information has revolutionized studies of nutrient flow and

97 niche ecology in a wide range of organisms (e.g. Fry 1988, Hobson and Welch 1992, Muschick

98 et al. 2012). In particular, nitrogen and carbon stable isotopes have been found to reflect trophic

99 position: both $\delta^{15} \mathrm{~N}$ and $\delta^{13} \mathrm{C}$ tend to increase in a predictable manner with each successive

100 trophic level (Post 2002, but see deVries et al. 2015). Stable isotopes have also been used to

101 track nutrient flow, climatic shifts, and migration patterns in a variety of ecological systems (Best

102 and Schell 1996, Chamberlain et al. 1997, lacumin et al. 2005, McMahon et al. 2016). The

103 current study uses stable isotopes of $\mathrm{N}$ and $\mathrm{C}$ to assess the extent to which entire food webs

104 are influenced by the chemistry of their habitats. We chose to focus on spiders because they

105 are mobile generalist predators and encompass multiple trophic levels, from feeding on

106 herbivorous insects to specializing on the highest predator levels among Hawaiian arthropods

107 (other spiders). This substantial variation in trophic ecology allows us to test how functional and

108 trophic differences are reflected in isotopic signatures, and the extent to which the

109 biogeochemistry of a food web is determined by the chemistry of the immediate substrate. The

110 use of $\mathrm{N}$ and $\mathrm{C}$ stable isotopes is especially well suited to this study because of the predictable

111 manner in which both elements can reflect trophic position, and because of the importance of

112 nitrogen in ecosystem development (Boring et al. 1988).

113

114 We analyzed Hawaiian spiders belonging to two lineages within the adaptive radiation of long-

115 jawed orb-weavers (Tetragnatha, Tetragnathidae) and one lineage within the stick spiders

116 (Ariamnes, Theridiidae). The Tetragnatha radiation includes ca. 60 species, which display a

117 spectacular array of colors, shapes, sizes, behaviors, and ecological affinities not observed

118 elsewhere in the range of this genus (Blackledge and Gillespie 2004, Gillespie 2004, 2015). The

119 radiation consists of two major clades: one that spins webs for prey capture ("web builders"),

120 and another that has lost the web-spinning behavior and instead hunts actively (the "Spiny Leg"

121 clade; Gillespie 1991, 2002). Observational data indicate that both web-building and Spiny Leg 
122 Tetragnatha feed on a mixture of insect herbivores and predators (Binford 2001), although the 123 exact composition of these spiders' diets has not yet been fully characterized. The Hawaiian

124 Ariamnes, currently represented by 11 known species across the Hawaiian Islands (Gillespie 125 and Rivera 2007), are also ecologically diverse and largely araneophagic (i.e., preying on other 126 spiders) (Gillespie et al 2018). Like Tetragnatha, these spiders are exclusively nocturnal, and 127 like the Spiny Leg Tetragnatha, they hunt without the use of a web.

129 Given the contrasting hunting strategies (web-building versus active hunting) and trophic 130 positions (generalist versus araneophagic) across these spider lineages, the three groups vary 131 predictably in their position in the food web, from largely feeding on primary consumers (i.e., 132 insect herbivores) to exclusively feeding on secondary and higher consumers (i.e., spiders). 133 Within this system, we tested the hypothesis that isotopic signatures of spiders should reflect 134 the biogeochemistry of their respective habitats, from young to older in the Hawaiian 135 chronosequence. Thus, not only should the different spider lineages illustrate now-standard 136 expectations for isotope signatures associated with rising trophic levels, but the trophic ecology 137 of the entire food web should reflect changes in soil chemistry across the chronosequence. In 138 particular, given that $\delta^{15} \mathrm{~N}$ in the soil increases during the building phase of the Hawaiian 139 ecosystems (Vitousek et al. 1997), we expect $\delta^{15} \mathrm{~N}$ to be lowest in the spiders at the youngest $140(200-750 \mathrm{y})$ site and highest in the spiders at the oldest $(20,000 \mathrm{y})$ site. 


\section{Methods}

\section{Study sites}

143 Hawaii's sequential age structure has made it an ideal system for previous studies on soil

144 evolution and nutrient cycling, wherein the Long Substrate Age Gradient (LSAG) was

145 established (Crews et al. 1995, Vitousek 2004). This study focuses on Hawai'i Island, the

146 youngest in the archipelago, because the largest possible range of $\mathrm{N}$ availabilities is expected to

147 be found there: soil nitrogen is lowest in the youngest substrates and peaks in the older

148 substrates on Hawai'i Island before declining on the older islands (Vitousek et al. 1995).

149

150

Specimens were collected on the windward side of Hawai'i Island under permits from the State

of Hawaii Department of Land and Natural Resources (endorsement \# FHM14-349) and the

National Park Service (study \# HAVO-00425). Three sites of different substrate age, chosen for

their comparable elevations and climates as well as the overlap of two of the sites ('Ola'a and

Laupāhoehoe) with those characterized based on soils (Vitousek et al. 1997), were sampled

155 (see Figure 1). Substrate ages were determined based on data from the United States

156 Geological Survey (Sherrod et al. 2007) and from the LSAG (Crews et al. 1995, Vitousek 2004).

157 All three sites are wet/mesic forest dominated by Metrosideros polymorpha and Acacia koa in

158 the canopy, with Cibotium spp. dominating the understory. The sites range from 1180 to $1390 \mathrm{~m}$

159 in elevation, with mean annual temperatures of 13.9 to 15.4 degrees Celsius and mean annual

160 rainfall of 3035 to $3090 \mathrm{~mm}$ (Giambelluca et al. 2014).

161

162 Upper Waiakea is a very young site on a 200- to 750-year-old lava flow in a stratified matrix of

163 differently-aged substrates within the Upper Waiakea Forest Reserve, off of Stainback Highway 
164 on Mauna Loa. 'Ola'a Forest is on an older lava flow on Kilauea, situated within Hawai'i

165 Volcanoes National Park. The trees in 'Ola'a are rooted in a thick layer of tephra of

166 approximately 2,100 years old (Vitousek 2004), beneath which is an older flow of 5,000-11,000

167 y (see Figure 1). Although the United States Geological Survey (USGS) classifies this substrate

168 as 5,000-11,000 y, we consider its biota to be influenced by the chemical properties of the

1692,100 -year-old tephra in which the forest is rooted. 'Ola'a is therefore approximately one order

170 of magnitude older than Upper Waiakea, yet is located just $11.5 \mathrm{~km} \mathrm{~S}$ of the younger site. This

171 proximity makes the two sites especially useful for measuring effects of habitat age on a small

172 geographical scale. The oldest site in this study is Laupāhoehoe, located in the Laupāhoehoe

173 Experimental Forest Unit on Mauna Kea. While USGS data (Sherrod et al. 2007) estimate the

174 lava flow age at 5,000-11,000 y, the sampling locality overlaps with an LSAG site which has

175 been studied in great detail and whose forest is rooted in a layer of soil believed to be

176 approximately 20,000 y old (Vitousek 2004, Vitousek et al. 2009). We therefore follow the LSAG

177 classification of 20,000 y for Laupāhoehoe.

178

179 Collections at each site were centered at the following coordinates, with searches extending up 180 to $100 \mathrm{~m}$ in any direction:

181 - Upper Waiakea: $19.562^{\circ} \mathrm{N}, 155.272^{\circ} \mathrm{W}$

182 - 'Ola'a: $19.462^{\circ} \mathrm{N}, 155.248^{\circ} \mathrm{W}$

183 - Laupāhoehoe: $19.922^{\circ} \mathrm{N}, 155.301^{\circ} \mathrm{W}$

184

185 Specimen collection

186 Six species of Tetragnatha spiders (Tetragnatha anuenue, T. brevignatha, T. hawaiensis, T.

187 perkinsi, T. quasimodo and the undescribed species T. "golden dome") and two species of 
188 189 190 191 192 193 194 195 196

197 198 199

200

201 202 203

204 205 206 207 208 209

210 Stable isotope analysis

Ariamnes spiders (Ariamnes hiwa and $A$. waikula) were collected in the field from 11 March to 18 April 2015, and from 6 to 15 February 2016. All study species are morphologically distinct and can be easily identified in the field. Plant samples were leaves of dominant or common forest vegetation (Metrosideros polymorpha, Cibotium spp. and Cheirodendron spp.), all of which are also easily identified on sight. After a preliminary analysis, it was determined that leaf litter should be added to the study in order to help explain differences in carbon isotope values. Unfortunately, permitting and time constraints only allowed for leaf litter to be collected from the youngest site (Upper Waiakea) on 15 October 2016.

Spiders were individually hand-captured into clean plastic snap-cap vials which were labeled on the outside with unique identifiers, while plant leaves were clipped off with scissors and stored in labeled paper envelopes. In Upper Waiakea, leaf litter was also collected from the bases of $M$. polymorpha trees and placed in paper envelopes. Leaves were air-dried in their envelopes in a sealed container of silica for three weeks prior to processing. Leaf litter was dried in a $60^{\circ} \mathrm{C}$ oven overnight.

Spiders were photographed up close using a Nikon D5200 with an AF-S DX Micro-NIKKOR 40 $\mathrm{mm} \mathrm{f} / 2.8 \mathrm{~g}$ lens and a Speedlight SB-400 flash from both dorsal and lateral angles. This created a photographic voucher and allowed for visual identification of species, sex, and maturity.

Spiders were killed overnight in a freezer and air-dried in separate snap cap vials, each with one clean bead of silica gel, before being transferred to individual 2-mL centrifuge tubes. 
213 (S. Mambelli, UC Berkeley Center for Stable Isotope Biogeochemistry, pers. comm., 2014). Due

214 to the spiders' small body size (ranging from ca. 0.4 to $5 \mathrm{mg}$ dry weight for the majority of

215 specimens), it was not feasible to obtain sufficient material from individual body parts, although

216 it has been found that different spider tissues can undergo different isotopic turnover rates

217 (Belivanov and Hambäck 2015). Therefore, in order to control for possible variation in isotopic

218 turnover among tissue types, the spiders' entire bodies were analyzed. When spiders exceeded

2192.5 mg dry weight, they were homogenized (powdered and mixed) with a mortar and pestle, and

220 a 1.5-mg sample of the homogenized tissue was used. For smaller spiders $(<2.5 \mathrm{mg})$, the

221 whole intact body was packed into the tin capsule in order to avoid excessive loss of material.

222 Plant leaves were individually homogenized in a Mini-Beadbeater (BioSpec Model 8) in 7-mL

223 tubes with stainless steel ball bearings, then weighed into $9 \times 5 \mathrm{~mm}$ tin capsules. Due to the

224 relatively low $\mathrm{N}: \mathrm{C}$ ratio of plants, $6 \mathrm{mg}$ of material was weighed out for each leaf sample. Leaf

225 litter was processed in the same manner as plant leaves.

226

227 Samples were analyzed for nitrogen and carbon content (\% dry weight) and nitrogen and

228 carbon stable isotope ratios via elemental analyzer/continuous flow isotope ratio mass

229 spectrometry using a CHNOS Elemental Analyzer (model: Vario ISOTOPE cube, Elementar,

230 Hanau, Germany) coupled with an IsoPrime 100 mass spectrometer (Isoprime Ltd, Cheadle,

231 UK). The isotope ratio is expressed in "delta" notation (in parts per thousand, or \%o units). The

232 isotopic composition of a material relative to that of a standard on a per mill deviation basis is

233 given by $\delta^{15} \mathrm{~N}\left(\right.$ or $\left.\delta^{13} \mathrm{C}\right)=\left(\mathrm{R}_{\text {sample }} / \mathrm{R}_{\text {standard }}-1\right) \times 1,000$, where $\mathrm{R}$ is the molecular ratio of heavy to

234 light isotopes. The standard for nitrogen is air. The standard for carbon is V-PDB. The reference

235 material NIST SMR 1547 (peach leaves) was used as calibration standard (long-term precision

236 [since 2000] using this standard is $+/-0.07 \%$ for both $\mathrm{N}$ and $\mathrm{C}$ isotope analyses). All isotope

237 analyses were conducted at the Center for Stable Isotope Biogeochemistry at the University of 
238 California, Berkeley. Long-term external precision based on reference material NIST SMR

$2391577 \mathrm{~b}$ (bovine liver) is $0.15 \%$ and $0.10 \%$, respectively, for $\mathrm{N}$ and $\mathrm{C}$ isotope analyses.

240

\section{Data analysis}

242 Results from the isotopic analysis were categorized into the following functional groups: "plant"

243 (foliar samples of the genera Metrosideros, Cibotium and Cheirodendron); "Spiny Leg" (Spiny

244 Leg Tetragnatha species: T. anuenue, T. brevignatha and T. quasimodo); "web" (Tetragnatha

245 hawaiensis, T. perkinsi, and the undescribed species nicknamed T. "golden dome"); and

246 "Ariamnes" (Ariamnes hiwa and A. waikula, the two species found on Hawai'i Island (Gillespie

247 and Rivera 2007)). Although all spider species were initially analyzed separately, the results

248 showed that the data grouped taxa together, largely in accordance with functional group.

249 Because members of one group (e.g. web-builders) were closer to one another than to other

250 groups (e.g. Spiny Leg), we chose to focus on these broader ecological categories - functional

251 groups - rather than species.

252

253 Effects of site and functional group on $\delta^{15} \mathrm{~N}$ and $\delta^{13} \mathrm{C}$ were tested using a 2-way Anova allowing

254 for interaction (with site and functional group as factors) on R statistical software (version 3.2.2,

255 64-bit). Main effects were then analyzed separately: we tested 1) effect of site within each

256 functional group and 2) effect of functional group within each site. When significant differences

257 were found, pairwise comparisons were made using Tukey's honest significant difference test

258 (Tukey 1949). 


\section{Results}

260 We found a significant interaction between site and functional group for $\delta^{15} \mathrm{~N}(\mathrm{~F}=8.615, p<$ 261 0.001), but not for $\delta^{13} \mathrm{C}(\mathrm{F}=1.841, \mathrm{p}=0.092$; Table 1). Significant main effects were found for 262 all variables tested: site for $\delta^{15} \mathrm{~N}(\mathrm{~F}=692.1, \mathrm{p}<0.001)$, functional group for $\delta^{15} \mathrm{~N}(\mathrm{~F}=113.6, p<$ 263 0.001), site for $\delta^{13} \mathrm{C}(\mathrm{F}=55.51, \mathrm{p}<0.001)$, and functional group for $\delta^{13} \mathrm{C}(\mathrm{F}=95.15, \mathrm{p}<0.001)$. 264

265

\section{Main effects: Site}

266 For $\delta^{15} \mathrm{~N}$, a significant site effect was found within all functional groups (plants: $\mathrm{F}=78.74, \mathrm{p}<$ 267 0.001; Spiny Leg: $F=446.9, p<0.001$; web-builders: $F=216.6, p<0.001 ;$ Ariamnes: $F=$ 268 80.87, $\mathrm{p}<0.001$; Table 2 and Figure 2). We performed a Tukey's HSD test to reveal pairwise 269 differences among sites. $\delta^{15} \mathrm{~N}$ showed a clear pattern of stepwise increase with substrate age 270 (lowest in Upper Waiakea [200-750 y], intermediate in 'Ola'a [2,100 y], and highest in 271 Laupāhoehoe [20,000 y]). This pattern held true for every functional group; the only comparison 272 not found to be significant was 'Ola'a vs. Laupāhoehoe within Ariamnes (Tukey’s adjusted $p=$ 273 0.203).

274

275 For $\delta^{13} \mathrm{C}$, a significant site effect was found within every functional group except for plants 276 (plants: $F=0.7997, p=0.482 ;$ Spiny Leg: $F=5.681, p=0.005 ;$ web-builders: $F=31.91, p<$ 277 0.001; Ariamnes: $\mathrm{F}=36.62, \mathrm{p}<0.001$; Table 2 and Figure 3). Among the three groups of 278 spiders, $\delta^{13} \mathrm{C}$ was significantly lower in Laupāhoehoe $(20,000$ y) than in 'Ola'a (2,100 y). 


\section{Main effects: Functional group}

280 A significant functional group effect was found in all sites for $\delta^{15} \mathrm{~N}$ (Upper Waiakea: $\mathrm{F}=68.38, \mathrm{p}$ $281<0.001$; 'Ola'a: $F=34.23, p<0.001$; Laupāhoehoe: $F=28.90, p<0.001$; Table 3 and Figure 282 2). A Tukey's HSD test found significant differences among every pair of groups except for the 283 following pairs in Upper Waiakea: web-builders vs. Ariamnes (Tukey's adjusted p-value = 284 0.071), web-builders vs. leaf litter (Tukey's adjusted p-value $=0.998$ ), and Ariamnes vs. leaf 285 litter (Tukey's adjusted p-value $=0.512$ ).

287 For $\delta^{13} \mathrm{C}$, a significant functional group effect was found at all three sites (Upper Waiakea: $\mathrm{F}=$ 288 36.42, $p$ < 0.001; 'Ola'a: $F=41.29, p<0.001$; Laupāhoehoe: $F=41.48, p<0.001$; Table 3 and Figure 3). At all sites, plants were significantly lower in $\delta^{13} \mathrm{C}$ than the next-lowest trophic level, 290 Spiny Leg spiders (consumers); therefore, the results of pairwise comparisons between plants 291 and more distant functional groups (web-builders and Ariamnes) are not included in the table of 292 Tukey's HSD results. In 'Ola'a (2,100 y), Spiny Leg spiders had significantly lower $\delta^{13} \mathrm{C}$ than 293 either web-builders or Ariamnes (Tukey's adjusted p-value < 0.001). In Upper Waiakea (200294750 y), although there was no significant difference between Ariamnes and either of the 295 Tetragnatha functional groups, the Spiny Leg Tetragnatha were significantly lower in $\delta^{13} \mathrm{C}$ than web-builders (Tukey's adjusted p-value < 0.001). In Laupāhoehoe $(20,000$ y), no significant 297 difference was found between any pair of spider groups.

\section{Discussion}

299 The results from this study provide a novel perspective on how changes in the substrate 300 chemistry of the terrestrial land surfaces across a chronosequence of developing ecosystems are propagated up through an entire food web. To our knowledge this is also the first study to 
302 characterize the isotopic signatures of different ecological groups represented by exemplary 303 adaptive radiations of spiders in Hawaii.

304

305 Parallel shifts in isotopic signature across the chronosequence of 306 ecosystem development

307 Previous work on the ecological characteristics of forests across the chronosequence has detailed the evolution of Hawaiian ecosystems in the context of soil properties and vegetation (Vitousek et al. 1989, 1995, 1997). Our results show that the chemical signatures of nutrient availability that characterize a given site are borne all the way up to the highest trophic levels -

311 top predators - on a Hawaiian chronosequence. Indeed, the $\delta^{15} \mathrm{~N}$ values of spiders perfectly

312 match expectations for their respective habitats. Where nitrogen is most limited - at the

313 youngest site (Upper Waiakea) - spiders have the lowest values of $\delta^{15} \mathrm{~N}$; as substrate age and

314 nitrogen availability increase, so too does the $\delta^{15} \mathrm{~N}$ of spiders. This makes sense physiologically

315 because when nitrogen is very limited, the lighter isotope $\left({ }^{14} \mathrm{~N}\right)$ is not as easily lost in reactions,

316 and is instead retained at a greater rate in an organism's tissues (Austin and Vitousek 1998).

317 Conversely, when biologically available nitrogen is very abundant, ${ }^{14} \mathrm{~N}$ is readily lost (e.g. in

318 excretion), leaving behind a greater proportion of the heavier ${ }^{15} \mathrm{~N}$ in the organism's tissues.

319 Thus, our results support the hypothesis that the isotopic signatures of the spiders - as well as

320 the plants - track the changes in the geological age of the islands (Sherrod et al. 2007) and the 321 associated changes in nitrogen in soils across the Hawaiian chronosequence measured by

322 Vitousek et al. (1997).

323

324 While it might not be surprising that the increase in $\delta^{15} \mathrm{~N}$ in the spiders tracks the increases in 325 plants across the geological gradient, the fact that the relationship is so tight is remarkable, as it 326 suggests that even higher-level consumers (predators) reflect the $\delta^{15} \mathrm{~N}$ of the immediate site. 
327 This result is especially notable because it was found in cursorial animals, which, because of

328 their mobility, might be expected to show only a weak association with the substrates on which

329 they were collected. Instead, the spiders carry clear signatures of their immediate ecosystem.

330 Given that the sites that were sampled are in very close proximity (11.5 km between 'Ola'a and

331 Upper Waiakea), and not separated by any significant physical barrier, the results suggest an

332 extraordinary level of isolation among spider populations. This has implications for the

333 mechanisms by which the Tetragnatha adaptive radiation may have arisen: Isolation between

334 populations separated by short distances can serve as a crucible for evolution (Carson et al.

335 1990). Perhaps the same mechanisms that are currently at work on Hawaii's youngest Island

336 also led to the rise of the approximately 60 endemic Tetragnatha species found across the

337 archipelago today. Results for Ariamnes were similar, all higher than the other spider lineages,

338 and values increasing with substrate age (though the increase from 'Ola'a to Laupahoehoe was

339 not significant, presumably due to a relatively small sample size $(n=9)$ at these sites).

340 Ariamnes, like the Tetragnatha, has undergone a substantial, though smaller at 11-16 species,

341 adaptive radiation across the islands (Gillespie et al. 2018).

342

343 The carbon isotope data show a less clear pattern than nitrogen, but nevertheless indicate site-

344 specific differences among the spiders. Notably, the plant samples did not differ significantly in

$345 \delta^{13} \mathrm{C}$ among the three sites, suggesting that perhaps $\delta^{13} \mathrm{C}$ does not accurately reflect nutrient

346 differences among the substrates. By contrast, $\delta^{15} \mathrm{~N}$ appears to strongly reflect nutrient

347 availability at the different sites. However, spiders did consistently show higher $\delta^{13} \mathrm{C}$ in 'Ola'a

$348(2,100 \mathrm{y})$ than in Laupāhoehoe $(20,000 \mathrm{y})$. Thus, the relationship between baseline (plant)

349 signatures and higher predator (spider) signatures is weaker in carbon than in nitrogen. This

350 suggests that spiders at the three sites may not be consuming exactly the same assemblages of

351 prey, perhaps due to variations in the availability of different insect (potential prey) species at 
352 different sites. A detailed study of the precise compositions of these spiders' diets, using either 353 molecular gut content analysis (e.g. Krehenwinkel et al. 2017) or an isotopic mixing model with

354 robust sampling of the entire arthropod community, could greatly enhance our understanding of

355 the processes that account for the differences in $\delta^{13} \mathrm{C}$ among spider populations.

356

357

\section{Trophic positions}

358

359

360

361

362

363

364

365

366

367

368

369

370

371

372

373

374

375

376

Our stable nitrogen isotope data reflect the different functional roles and trophic positions of the Hawaiian spiders. Our results are consistent with the enrichment of the heavier isotope, ${ }^{15} \mathrm{~N}$, at higher trophic levels, with plants having the lowest values of $\delta^{15} \mathrm{~N}$, Tetragnatha having intermediate values, and the spider-eating Ariamnes having the highest. Additionally, we found that the $\delta^{15} \mathrm{~N}$ of the Spiny Leg (cursorial) spiders was consistently lower than that of webbuilding Tetragnatha. A simple explanation for the difference in $\delta^{15} \mathrm{~N}$ in cursorial vs. web-building spiders may be that the different functional groups consume different prey. Cursorial spiders are likely to interact with abundant insect herbivores, while web-builders may trap a larger proportion of flying insects at higher trophic levels, such as hymenopteran or dipteran parasitoids, decomposers, or predators. This dietary difference has been used to explain the phenomenon of a higher $\delta^{15} \mathrm{~N}$ in web-builders compared to cursorial spiders in a forest hedge community (Sanders et al. 2015). Another possible explanation is that the difference is due to the manufacturing of the orb web itself. Given that webs are an excretory product, and that excretion tends to favor the lighter ${ }^{14} \mathrm{~N}$, it may be that the higher levels of "excretion" lead to an enrichment in ${ }^{15} \mathrm{~N}$ in the bodies of web-builders compared with cursorial spiders. A number of previous studies suggest such an effect. For example, across a community of web-building riparian spiders, lower $\delta^{15} \mathrm{~N}$ was found in Miagrammopes (Uloboridae; Kelly et al. 2015), a genus characterized by a reduced capture web (often just a single line; Lubin et al. 1978), than in other spiders. Likewise, a study of niche width across a guild of spiders showed that cursorial 
377 spiders consistently had the lowest $\delta^{15} \mathrm{~N}$, while orb web spiders had the highest (Sanders et al.

378 2015). In each of these systems, the cursorial spiders showed the highest levels of intraguild

379 predation (i.e. feeding on other spiders), indicating that trophic position itself is insufficient to

380 explain the lower trophic position of the cursorial spiders relative to the web spinners. This

381 observation raises the possibility again that the web spinning process itself leads to $\delta^{15} \mathrm{~N}$

382 enrichment. However, further data are clearly needed to determine which of these explanations

383 best accounts for the now recurring pattern of higher ${ }^{15} \mathrm{~N}$ in web-builders compared with

384 cursorial taxa.

385

386 The patterns we found in $\delta^{13} \mathrm{C}$ were less dramatic than in $\delta^{15} \mathrm{~N}$, but matched expectations. Foliar

387 samples consistently had the lowest $\delta^{13} \mathrm{C}$ of all functional groups. Spider values were

388 substantially offset from leaf values - approximately 4-5 per mill higher at all sites - which

389 suggests a complex food chain consisting of many trophic levels below the spiders. This is

390 plausible given that spider are obligate predators (secondary consumers), and therefore must

391 be trophically removed from plants by at least two levels. The conventional wisdom with $\delta^{13} \mathrm{C}$ is

392 "you are what you eat" (Hobson et al. 2010), meaning that most organisms are only slightly

393 enriched in ${ }^{13} \mathrm{C}$ relative to their diets, with standard published offsets of less than 1 per mill for

394 each successive trophic level (Post 2002). Indeed, meta-analysis of isotopic studies has found

395 an average discrimination factor of $\sim 0.3$ per mill from one trophic level to the next within

396 invertebrates (Caut et al. 2009), although it should be noted that many of the invertebrates

397 included in that meta-analysis are aquatic, and no "standard" $\delta^{13} \mathrm{C}$ offset for spiders or other

398 terrestrial arthropods has yet been established. In an effort to fill the large gap between plants

399 and spiders, we added samples of leaf litter from Upper Waiakea. The $\delta^{13} \mathrm{C}$ of leaf litter fit neatly

400 between leaves and spiders. This is to be expected given that the lighter ${ }^{12} \mathrm{C}$ is lost as respired

$401{ }^{12} \mathrm{CO}_{2}$ that is produced at a greater rate during decomposition, leaving the remaining litter 
402 relatively ${ }^{13} \mathrm{C}$ enriched (Dawson et al. 2002). Furthermore, this finding fits with previous studies 403 of Tetragnatha trophic ecology, wherein it was observed that tipulid flies comprise a large 404 proportion of the diet of Tetragnatha on Maui (Binford 2001, Blackledge et al. 2003). Because 405 tipulid larvae often feed on decomposing leaves (Williams 1942), it is reasonable to surmise that 406 tipulids' own $\delta^{13} \mathrm{C}$ values fall close to those of the leaf litter, and that spiders on Hawai'i Island 407 become relatively enriched in their $\delta^{13} \mathrm{C}$ composition when feeding on these insects.

408

409

\section{Link between ecosystem properties and evolutionary processes}

410 This study demonstrates that organisms at multiple tropic levels reflect the stoichiometric

411 changes in soil across the geological chronosequence of the island, from very young (200-750

$412 \mathrm{y})$ to older $(20,000 \mathrm{y})$. The importance of this result is that it shows that the evolutionary

413 processes associated with diversification are intimately linked to a landscape that, itself,

414 changes through time. The detailed work of Vitousek et al. $(1989,1995,1997,2009)$ documents

415 the pattern of change in soil chemistry over extended time periods: Nitrogen and phosphorus 416 increase almost linearly with time in the early stages of substrate development (up to $20,000 \mathrm{y}$

417 for nitrogen and 150,000 y for phosphorus); this increase then levels off and declines on the 418 oldest islands (4 my).

419

420 At the same time, it is now well established that organismal diversity increases over time during 421 the early stages of formation of an island archipelago (Whittaker 2008, Lim \& Marshall 2017), 422 and that higher trophic levels depend on lower levels in island community assembly (Simberloff 423 \& Wilson 1970), yet explanations for such patterns have, as yet, considered only area and age 424 of the landscape. The documentation of peaks of diversity on middle aged islands of the 425 Hawaiian Archipelago has been explained variously based on the interaction between age and 426 area (Gillespie \& Baldwin 2010, Lim and Marshall 2017). Notably missing from these studies is 
427 a link between evolutionary processes of diversification and shifts in nutrient availability

428 associated with ecosystem succession. That organisms in Hawaii are intimately reflective of the

429 ecosystem properties of their immediate habitat demonstrates that changes in nutrients

430 associated with the island chronosequence are propagated through trophic and functional

431 groups of entire biological communities. While initial work has begun to address the ecosystem

432 consequences of evolutionary change (Elser et al. 2003, Laiolo et al. 2015), this study provides

433 preliminary insights into how ecosystem change may affect processes of evolution.

\section{Conclusions}

435 Variation in $\delta^{15} \mathrm{~N}$ data indicates that different spider lineages reflect their different functional

436 roles and trophic positions in Hawaiian food webs, from those feeding largely on primary

437 consumers to those feeding exclusively on secondary and higher consumers. Importantly, the

438 relationships between these groups, in terms of their $\delta^{15} \mathrm{~N}$, remain strong across the

439 chronosequence. Not only do the spiders' relative values of $\delta^{15} \mathrm{~N}$ show the same pattern at each

440 site, but their isotopic signatures also reflect the availability of nitrogen at different sites from

441 younger to older ecosystems. The tight relationship between $\mathrm{N}$ availability, plant isotopic values,

442 and spider isotopic values strongly suggests that the spiders are dispersal-limited and their

443 populations are isolated from one another, even across short distances. Such isolation may be

444 an important mechanism of speciation within the Tetragnatha adaptive radiation. This study

445 shows that these evolving lineages of spiders are intimately associated with the properties of

446 their ecosystem, which is also changing. The tight connection between the organisms and the

447 characteristics of their substrate highlights the importance of considering the role of soil

448 properties, particularly chemistry, in addition to age and area, to understand how biodiversity

449 accumulates over time. 


\section{Acknowledgements}

451 We thank Stefania Mambelli and Wenbo Yang for their help with the stable isotope analyses.

452 We also thank our colleagues on the Dimensions team for invaluable assistance with logistics in

453 the field; the staffs of the Hawaii National Park Service and Natural Area Reserve System for

454 help with permits; Charles Griswold and Alexandra Rueda Esteban for assisting with sample

455 collection; and Natalie Graham for collecting leaf litter. We are deeply grateful to the reviewers

456 and editors who provided helpful feedback on an earlier submission of this paper.

\section{References}

458 Austin AT, Vitousek PM. 1998. Nutrient dynamics on a precipitation gradient in Hawai'i. $459 \quad$ Oecologia 113: 519-529.

460 Belivanov YK, Hambäck PA. 2015. The time scale of isotope signals in spiders: molting the 461 remains of a previous diet. - Entomologia Experimentalis et Applicata 156: 271-278.

462

463

464

465

466

467

468

469

Best PB, Schell DM. 1996. Stable isotopes in southern right whale (Eubalaena australis) baleen as indicators of seasonal movements, feeding and growth. - Marine Biology 124: 483494.

Binford GJ. 2001. Differences in venom composition between orb-weaving and wandering Hawaiian Tetragnatha (Araneae). - Biological Journal of the Linnean Society 74: 581595.

Blackledge TA, Binford GJ, Gillespie RG. 2003. Resource use within a community of Hawaiian spiders (Araneae: Tetragnathidae). - Annales Zoologici Fennici 40: 293-303. 
470 Blackledge TA, Gillespie RG. 2004. Convergent evolution of behavior in an adaptive radiation of $471 \quad$ Hawaiian web-building spiders. - Proceedings of the National Academy of Sciences 472 101: 16228-16233.

473 Boring LR, Swank WT, Waide JB, Henderson GS. 1988. Sources, fates, and impacts of nitrogen 474 inputs to terrestrial ecosystems: review and synthesis. - Biogeochemistry 6: 119-159.

475 Carson HL, Clague DA. 1995. Geology and biogeography of the Hawaiian Islands. - In: Wagner 476 WL and Funk VA (eds), Hawaiian biogeography: evolution on a hot spot archipelago. 477 Smithsonian Institution Press, pp. 14-29.

478 Carson HL, Lockwood JP, Craddock, EM. 1990. Extinction and recolonization of local 479 populations on a growing shield volcano. - Proceedings of the National Academy of $480 \quad$ Sciences 87: 7055-7057.

481 Caut S, Angulo E, Courchamp F. 2009. Variation in discrimination factors $\left(\Delta^{15} \mathrm{~N}\right.$ and $\left.\Delta^{13} \mathrm{C}\right)$ : the 482 effect of diet isotopic values and applications for diet reconstruction. - Journal of Applied $483 \quad$ Ecology 46: 443-453.

484 Chamberlain CP, Blum JD, Holmes RT, Feng X, Sherry TW, Graves GR. 1997. The use of 485 isotope tracers for identifying populations of migratory birds. - Oecologia 109: 132-141.

Crews TE, Kitayama K, Fownes JH, Riley RH, Herbert DA, Mueller-Dombois D, Vitousek PM.

487 1995. Changes in soil phosphorus fractions and ecosystem dynamics across a long chronosequence in Hawaii. - Ecology 76: 1407-1424.

Dawson TE, Mambelli S, Plamboeck AH, Templer PH, Tu KP. 2002. Stable isotopes in plant ecology. - Annual Review of Ecology and Systematics 33: 507-559. discrimination factors in mantis shrimp crustaceans. - Plos One 10: e0122334. 
493 Doblas-Miranda E, Wardle DA, Peltzer DA, Yeates GW. 2008. Changes in the community

494 structure and diversity of soil invertebrates across the Franz Josef Glacier

495 chronosequence. - Soil Biology and Biochemistry 40: 1069-1081.

496 Elser JJ, Acharya K, Kyle M, Cotner J, Makino W, Markow T, Watts T, Hobbie S, Fagan W,

497 Schade J, Hood J, Sterner RW. 2003. Growth rate-stoichiometry couplings in diverse

498 biota. - Ecology Letters 6: 936-943.

499 Fry B. 1988. Food web structure on Georges Bank from stable C, N, and S isotopic

$500 \quad$ compositions. - Limnology and Oceanography 33: 1182-1190.

501 Giambelluca TW, Shuai X, Barnes ML, Alliss RJ, Longman RJ, Miura T, Chen Q, Frazier AG,

502 Mudd RG, Cuo L, Businger AD. 2014. Evapotranspiration of Hawai'i. Final report

503 submitted to the U.S. Army Corps of Engineers-Honolulu District and Commission on

504 Water Resource Management, State of Hawai'i.

505 Gillespie RG. 1991. Hawaiian spiders of the genus Tetragnatha: I. Spiny leg clade. - Journal of $506 \quad$ Arachnology 19: 174-209.

507 Gillespie RG. 2002. Hawaiian Spiders of the Genus Tetragnatha: IV: new, small species in the 508 spiny leg clade. - Journal of Arachnology 30: 159-172.

509 Gillespie RG. 2004. Community assembly through adaptive radiation in Hawaiian spiders. -

$510 \quad$ Science 303: 356-359.

511 Gillespie RG. 2015. Island time and the interplay between ecology and evolution in species 512 diversification. - Evolutionary Applications 9: 53-73.

513 Gillespie RG, Baldwin BG. 2010. Island biogeography of remote archipelagoes. - In: Losos, J.

514 B. and Ricklefs, R. E. (eds), The theory of island biogeography revisited. Princeton

$515 \quad$ University Press, pp. 358-387. 
516 Gillespie RG, Benjamin SP, Brewer MS, Rivera MAJ, Roderick GK. 2018. Repeated

517 diversification of ecomorphs In Hawaiian stick spiders. Current Biology. In press.

518 Gillespie R, Rivera M. 2007. Free-living spiders of the genus Ariamnes (Araneae, Theridiidae) in $519 \quad$ Hawaii. - Journal of Arachnology 35: 11-37.

520 Gruner DS. 2007. Geological age, ecosystem development, and local resource constraints on 521 arthropod community structure in the Hawaiian Islands. - Biological Journal of the $522 \quad$ Linnean Society 90: 551-570.

523 Hobson KA, Barnett-Johnson R, Cerling T. 2010. Using isoscapes to track animal migration. 524 In: West, J. B. et al. (eds), Isoscapes: understanding movement, pattern, and process on $525 \quad$ Earth through isotope mapping. Springer, pp. 273-298.

526 Hobson KA, Welch HE. 1992. Determination of trophic relationships within a high Arctic marine 527 food web using delta-13-C and delta-15-N analysis. - Marine Ecology Progress Series $528 \quad 84: 9-18$

529 lacumin P, Davanzo S, Nikolaev V. 2005. Short-term climatic changes recorded by mammoth 530 hair in the Arctic environment. - Palaeogeography, Palaeoclimatology, Palaeoecology $531 \quad 218: 317-324$.

532 Kelly SP, Cuevas E, Ramírez A. 2015. Stable isotope analyses of web-spinning spider 533 assemblages along a headwater stream in Puerto Rico. - PeerJ 3: e1324.

534 Krehenwinkel H, Kennedy SR, Pekár S, Gillespie RG. 2017. A cost-efficient and simple protocol 535 to enrich prey DNA from extractions of predatory arthropods for large-scale gut content $536 \quad$ analysis by Illumina sequencing. - Methods in Ecology and Evolution 8: 126-134.

537 Laiolo P, Illera JC, Meléndez L, Segura A, Obeso JR. 2015. Abiotic, biotic, and evolutionary 538 control of the distribution of $\mathrm{C}$ and $\mathrm{N}$ isotopes in food webs. - The American Naturalist 539 185: 169-182. 
540 Lim JY, Marshall CR. 2017. The true tempo of evolutionary radiation and decline revealed on 541 the Hawaiian archipelago. - Nature 543: 710-713.

542 Lubin YD, Eberhard WG, Montgomery GG. 1978. Webs of Miagrammopes (Araneae:

$543 \quad$ Uloboridae) in the Neotropics. - Psyche 85: 1-23.

544 Matthews B, Narwani A, Hausch S, Nonaka E, Peter H, Yamamichi M, Sullam KE, Bird KC,

545 Thomas MK, Hanley TC, Turner CB. 2011. Toward an integration of evolutionary biology $546 \quad$ and ecosystem science. - Ecology Letters 14: 690-701.

547 McMahon KW, Thorrold SR, Houghton LA, Berumen ML. 2016. Tracing carbon flow through 548 coral reef food webs using a compound-specific stable isotope approach. - Oecologia $549 \quad 180: 809-821$.

550 Muschick M, Indermaur A, Salzburger W. 2012. Convergent evolution within an adaptive $551 \quad$ radiation of cichlid fishes. - Current Biology 22: 2362-2368.

552 Post DM. 2002. Using stable isotopes to estimate trophic position: models, methods, and 553 assumptions. - Ecology 83: 703-718.

554

555

556

557

558

559

560

561
Roderick GK, Croucher PJP, Vandergast AG, Gillespie RG. 2012. Species differentiation on a dynamic landscape: shifts in metapopulation genetic structure using the chronology of the Hawaiian archipelago. - Evolutionary Biology 39: 192-206.

Rominger AJ, Goodman KR, Lim JY, Armstrong EE, Becking LE, Bennett GM, Brewer MS, Cotoras DD, Ewing CP, Harte J, Martinez ND, O'Grady PM, Percy DM, Price DK, Roderick GK, Shaw KL, Valdovinos FS, Gruner DS, Gillespie RG, Ricklefs R. 2016. Community assembly on isolated islands: macroecology meets evolution. - Global Ecology and Biogeography 25: 769-780. 
562 Sanders D, Vogel E, Knop E. 2015. Individual and species-specific traits explain niche size and

563

564

565

566

567

568

569

570

571

572

573

574

575

576

577

578

579

580

581

582

583

584

$$
\text { functional role in spiders as generalist predators. - Journal of Animal Ecology 84: 134- }
$$

142.

Sherrod DR, Sinton JM, Watkins SE, Brunt KM. 2007. Geologic map of the state of Hawaii. - In: U.S. Geological Survey Open-File Report 2007-1089 [http://pubs.usgs.gov/of/2007/1089/].

Simberloff DS, Wilson EO. 1970. Experimental zoogeography of islands. A two-year record of colonization. - Ecology 51: 934-937.

Tukey JW. 1949. Comparing individual means in the analysis of variance. - Biometrics 5: 99114.

Vitousek PM. 2004. Nutrient cycling and limitation: Hawai'i as a model system. - Princeton University Press.

Vitousek PM, Shearer G, Kohl DH. 1989. Foliar N-15 natural abundance in Hawaiian rainforest patterns and possible mechanisms. - Oecologia 78: 383-388.

Vitousek PM, Turner DR, Kitayama K. 1995. Foliar nutrients during long-term soil development in Hawaiian montane rain forest. - Ecology 76: 712-720.

Vitousek PM, Chadwick OA, Crews T, Fownes J, Hendricks DM, Herbert D. 1997. Soil and ecosystem development across the Hawaiian Islands. - GSA Today 7: 1-9.

Vitousek PM, Asner GP, Chadwick OA, Hotchkiss S. 2009. Landscape-level variation in forest structure and biogeochemistry across a substrate age gradient in Hawaii. - Ecology 90: 3074-86.

Walker LR, Wardle D, Bardgett RD, Clarkson BD. 2010. The use of chronosequences in studies of ecological succession and soil development. - Journal of Ecology 98: 725-736. 
585 Wardle DA, Walker LR, Bardgett RD. 2004. Ecosystem properties and forest decline in $586 \quad$ contrasting long-term chronosequences. - Science 305: 509-513.

587 Wardle DA, Bardgett RD, Walker LR, Peltzer DA, Lagerström A. 2008. The response of plant 588 diversity to ecosystem retrogression: evidence from contrasting long-term $589 \quad$ chronosequences. - Oikos 117: 93-103.

590 Whittaker RJ, Triantis KA, Ladle RJ. 2008. A general dynamic theory of oceanic island 591 biogeography. - Journal of Biogeography 35: 977-994.

592 Williams FX. 1942. Biological studies in Hawaiian water-loving insects - Part III - Diptera or flies 593 - C, Tipulidae and Psychodidae. - Proceedings of the Hawaiian Entomological Society $594 \quad 11: 313-338$.

595 Williamson WM, Wardle DA, Yeates GW. 2005. Changes in soil microbial and nematode 596 communities during ecosystem decline across a long-term chronosequence. - Soil $597 \quad$ Biology and Biochemistry 37: 1289-1301.

598 


\section{Table $\mathbf{1}$ (on next page)}

2-way ANOVA results.

Results of 2-way ANOVA testing for effects of site, functional group, and site $\times$ functional group interaction on stable isotopes of samples. Significant effects are indicated in bold. 


\begin{tabular}{|c|l|l|l|l|}
\hline Isotope & Effect & $\mathrm{F}$ & $\mathrm{df}$ & $\mathrm{p}$-value \\
\hline \multirow{3}{*}{$\delta^{15} \mathrm{~N}$} & site & 692.1 & 2 & $<\mathbf{0 . 0 0 1}$ \\
\cline { 2 - 6 } & functional group & 113.6 & 4 & $<\mathbf{0 . 0 0 1}$ \\
\cline { 2 - 6 } & site:functional group & 8.615 & 6 & $<\mathbf{0 . 0 0 1}$ \\
\hline \multirow{3}{*}{$\delta^{13} \mathrm{C}$} & site & 55.51 & 2 & $<\mathbf{0 . 0 0 1}$ \\
\cline { 2 - 5 } & functional group & 95.15 & 4 & $<0.001$ \\
\cline { 2 - 5 } & site:functional group & 1.841 & 6 & 0.092 \\
\hline
\end{tabular}




\section{Table 2 (on next page)}

Main effects of site within functional group.

Main effects of site (substrate ages: Upper Waiakea, 200-750 y; 'Ola'a, 2,100 y;

Laupāhoehoe, 20,000 y) within functional group. Site was found to have a significant effect on both $\mathrm{C}$ and $\mathrm{N}$ isotope ratios of every functional group, with the exception of $\delta^{13} \mathrm{C}$ in plants. 


\begin{tabular}{|l|l|l|l|l|}
\hline Isotope & Comparison & $\mathbf{F}$ & $\mathbf{d f}$ & p-value \\
\hline \multirow{5}{*}{$\delta^{15} \mathrm{~N}$} & plants & 78.74 & 2 & $<\mathbf{0 . 0 0 1}$ \\
\cline { 2 - 5 } & Spiny Leg & 446.9 & 2 & $<\mathbf{0 . 0 0 1}$ \\
\cline { 2 - 5 } & web-builders & 216.6 & 2 & $<\mathbf{0 . 0 0 1}$ \\
\cline { 2 - 5 } & Ariamnes & 80.87 & 2 & $<\mathbf{0 . 0 0 1}$ \\
\hline \multirow{5}{*}{$\delta^{13} \mathrm{C}$} & plants & 0.7997 & 2 & 0.482 \\
\cline { 2 - 5 } & Spiny Leg & 5.681 & 2 & $\mathbf{0 . 0 0 5}$ \\
\cline { 2 - 5 } & web-builders & 31.91 & 2 & $<\mathbf{0 . 0 0 1}$ \\
\cline { 2 - 5 } & Ariamnes & 36.62 & 2 & $<\mathbf{0 . 0 0 1}$ \\
\hline
\end{tabular}




\section{Table 3(on next page)}

Main effects of functional group within site.

Main effects of functional group within site. Functional groups were found to differ significantly from one another in their isotope ratios of both $\mathrm{C}$ and $\mathrm{N}$ at all three sites. 


\begin{tabular}{|c|l|l|l|l|}
\hline Isotope & Site & F & df & p-value \\
\hline \multirow{3}{*}{$\delta^{15} \mathrm{~N}$} & Upper Waiakea $(200-750 \mathrm{y})$ & 68.38 & 4 & $<\mathbf{0 . 0 0 1}$ \\
\cline { 2 - 5 } & 'Ola'a $(2,100 \mathrm{y})$ & 34.23 & 3 & $<\mathbf{0 . 0 0 1}$ \\
\cline { 2 - 5 } & Laupāhoehoe $(20,000 \mathrm{y})$ & 28.90 & 3 & $<\mathbf{0 . 0 0 1}$ \\
\hline \multirow{3}{*}{$\delta^{13} \mathrm{C}$} & Upper Waiakea (200-750 y) & 36.42 & 4 & $<\mathbf{0 . 0 0 1}$ \\
\cline { 2 - 5 } & 'Ola'a (2,100 y) & 41.29 & 3 & $<\mathbf{0 . 0 0 1}$ \\
\cline { 2 - 5 } & Laupāhoehoe (20,000 y) & 41.48 & 3 & $<\mathbf{0 . 0 0 1}$ \\
\hline
\end{tabular}


Figure 1

Map showing field sites where samples were collected.

Locations of sites used in this study. Colors represent geology and lava flow age, determined by United States Geological Survey (Sherrod et al. 2007). Where applicable, substrate age classifications determined by the Long Substrate Age Gradient (LSAG, Crews et al. 1995) are included.

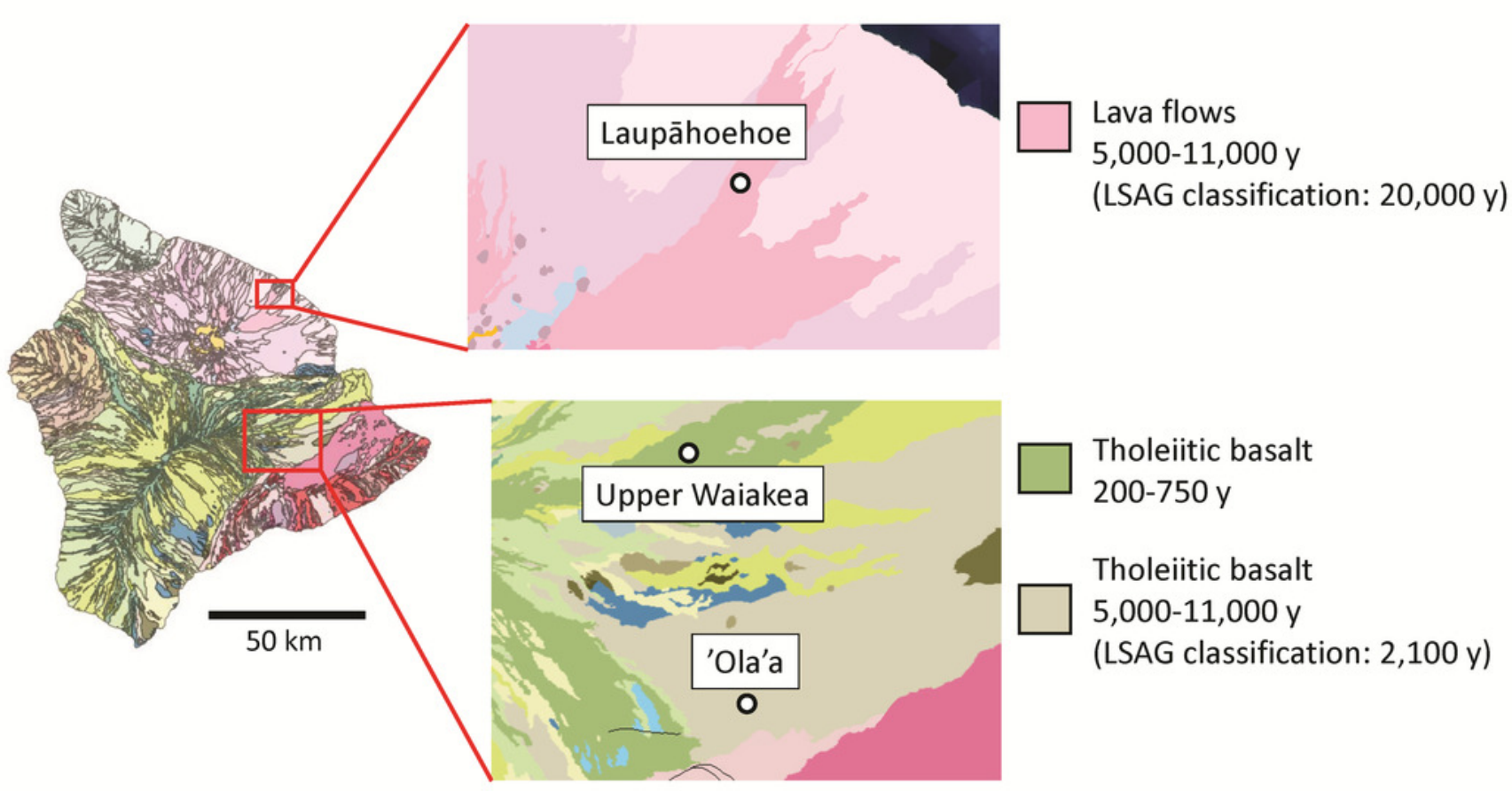


Figure 2

Boxplots showing nitrogen isotope ratios of functional groups across sites.

Nitrogen isotope ratio ( $\delta^{15} \mathrm{~N}$ in \%o units) of plant leaves (green), leaf litter (purple), Spiny Leg (brown), web-building (yellow) and Ariamnes (blue) spiders across sites of different ages.

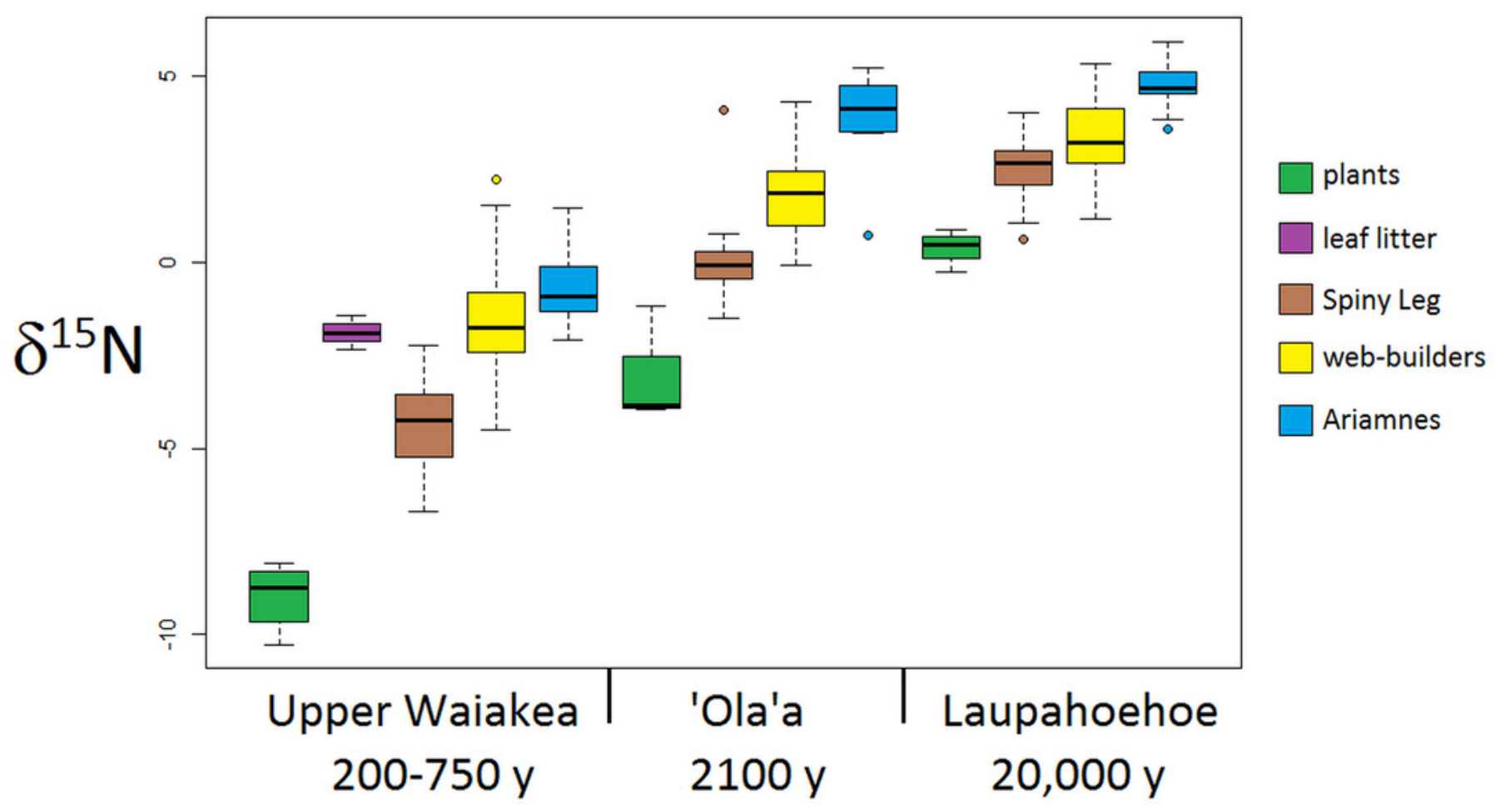


Figure 3

Boxplots showing carbon isotope ratios of functional groups across sites.

Carbon isotope ratio ( $\delta^{13} \mathrm{C}$ in $\%$ units) of plant leaves (green), leaf litter (purple), Spiny Leg (brown), web-building (yellow) and Ariamnes (blue) spiders across sites of different ages.

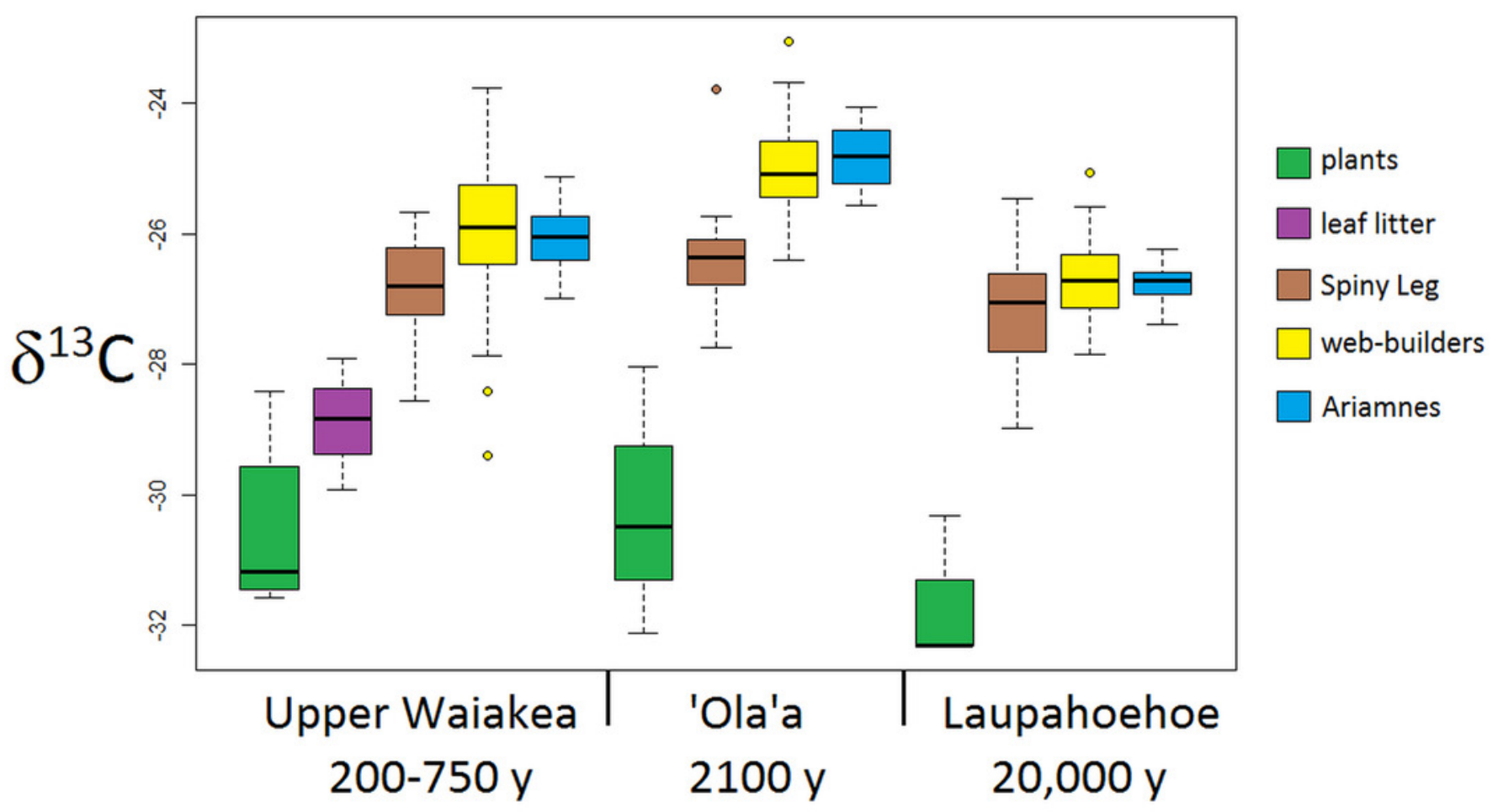

